\title{
Back Fat Layer Measurements by Ultrasonography in Camels - A Tool for Measuring the General Health Status
}

\section{Asim Faraz ${ }^{1 *}$, Syeda Maryam Hussain ${ }^{2}$, Annamaria Passantino ${ }^{3}$ and Michela Pugliese ${ }^{3}$}

${ }^{1}$ Department of Livestock and Poultry Production, Faculty of Veterinary Sciences, Bahauddin Zakariya University Multan, Pakistan

${ }^{2}$ Department of Livestock Production and Management, Pir Mehr Ali Shah Arid Agriculture University Rawalpindi, Pakistan

${ }^{3}$ Department of Veterinary Sciences, Polo Universitario Annunziata - Messina, University of Messina, Italy

*Corresponding Author: Asim Faraz, Department of Livestock and Poultry

Production, Faculty of Veterinary Sciences, Bahauddin Zakariya University Multan, Pakistan. E-mail: drasimfaraz@bzu.edu.pk
Received: November 16, 2021

Published: December 08, 2021

(C) All rights are reserved by Asim Faraz., et

al.

\begin{abstract}
Since 1950's ultrasound has been used extensively for measurements in different parts of the body, but the early techniques were very labor-intensive and slow. In 1970, the technology has been improved by the introduction of scanogram and SVC scanner. Recently by using new generations of the portable equipment that are originally designed for medical purposes, the real-time ultrasonic scanning (RTUS) has offered the potential to produce accurate and quick measurements at lower cost. The applications were described in livestock industry of North America. The computed tomography was proposed as the standard method for quantifying abdominal adiposity since 1990. There has been substantial variability in the relative accuracy while measuring the back-fat thickness by ultrasound so require a well-trained examiner and specific equipment. Ultrasonography is a very simple and reliable technique for measuring visceral and subcutaneous fat. In addition to this, ultrasonography is a quick and non-invasive technique having very good reproducibility rates with intra-examination variation less than $1 \%$ and lower costs than computed tomography scans. It is very first time in Pakistan, the back-fat layer measurement was measured by ultrasonography in camel herd where slaughtering can't be performed in breeding stock. This paper will be a useful addition in the field of camel science.
\end{abstract}

Keywords: Camel; Ultrasonography; Back Fat Layer; Desert; Pastoral

\section{Introduction}

Camels in Pakistan are very well adapted to their native environment and can sustain life in hot and harsh deserts [1]. The dromedary camel is a best source of milk and meat especially for those areas where production performance of other animals is adversely affected by the harsh environmental conditions [2-4]. This is due to its unique physiological characteristics that enable to tolerate higher temperatures, solar radiations, water scarcity, poor vegetation, and rough topography [5-7].

Ultrasonography is a very simple and reliable technique for measuring visceral and subcutaneous fat by showing a very strong correlation with both these adiposities when measured with a computed tomography scan $[8,9]$. As it allows the individual visualization of intra-abdominal (visceral) and subcutaneous fat so expected to be the most specific and reliable method [10]. proposed the ultrasonographic usage for the measurement of visceral adiposity for the first time as an alternative to computed tomography. According to [11] there has been substantial variability in the relative accuracy while measuring the back-fat thickness by ultrasound so require a well-trained examiner and specific equipment.

\section{Ultrasonography in camels}

[12] proposed the most reliable technique of ultrasonographic measurement of thickness of fat tissues. Aloka (SSD-900 by Tokyo, Japan) a linear array probe was used to perform ultrasonographic 
measurements in spine position. On the upper median abdomen, it was kept perpendicular to the skin and parallel to the skin in the midpoint between the xiphoid appendix and navel along the albaline about the liver surface, longitudinal scan was done. Subcutaneous fat thickness and area in both the longitudinal and transverse views were measured on the xiphoumbilical line.

In tracking the carcass merit and composition ultrasound used to be a substitute for serial slaughter. To project future cutability grades ultrasound measures can be used as back-fat thickness increases at continuous definite rates [13]. Ultrasound is very sensitive to detect subtle changes in fat thickness over time and can be used to check live animal changes in absolute fat thickness so might be used as an alternate to slaughter in research studies. In trials where back fat thickness of live animals must be reported, if careful in sonification and echo graphic interpretation is done, that could be accepted as equivalent to a carcass measure. Thickness of the subcutaneous fat layer was measured on the right side of the animal between the $12^{\text {th }}$ and $13^{\text {th }}$ rib over the longissimus muscle. In sonification was done with an Aloka (210 B-mode ultrasound system) which was equipped with a 5-MHz, 56-mm scanning width, and linear array trans-rectal transducer (UST-5813-5). On the monitor of this instrument the image portrayal was of same size as the animal dimensions. The couplant used was mineral oil, cattle were not clipped, and no stand-off pad was used. Usually, the next day cattle were re-measured with the previous measures concealed. To allow the biological increase in the fat thickness between two readings regression analysis was equally applied to adjust the mean value of the first reading to that of second. Several elements in the measurement protocol were seemed to reduce errors in the back-fat estimates by ultrasonography [14].

Ultrasonic scanning is very effective in carcass measurements prediction in animals. Fat depths can be measured very accurately as on the carcass and rump fat depths were about $85 \%$ of scanning measurements [15]. According to [16] sternal recumbency is the most suitable position to perform ultrasonographic examination and the technique is non-invasive having the advantage that it could be applied on sitting non-tranquilized camels. A greater correlation between carcass measurements and ultrasonography was obtained by some researchers at $3^{\text {rd }}$ and $4^{\text {th }}$ lumbar vertebrae $[17,18]$. While the most common site is $12^{\text {th }}$ and $13^{\text {th }}$ rib to evaluate the transverse fat and lion muscle depth in lambs as reported by [19]. To predict lean mass and fat yield the total tissue depth is a measurement included in carcass grading systems over the $12^{\text {th }}$ rib at $11 \mathrm{~cm}$ apart from the midline of carcass in Australia [20], Canada [21] and New Zealand [22]. Ultrasonic measurements are more accurate tool for evaluation of fat and total tissue depths in animals and when only the fat depth assessment is required then the site between 12 th and 13 th ribs seemed to be more appropriate for this measurement [23].

In very recent study [24], performed ultrasonographical procedures in Marecha camel calves and documented that sternal recumbency is the most suitable position to perform ultrasonographical examination. They measured the back-fat layer by ultrasonography in feedlot calves of breeding stock and found back fat layer measurement above $4 \mathrm{~mm}$ in all animals and further confirmed the results by relating with body condition scores.

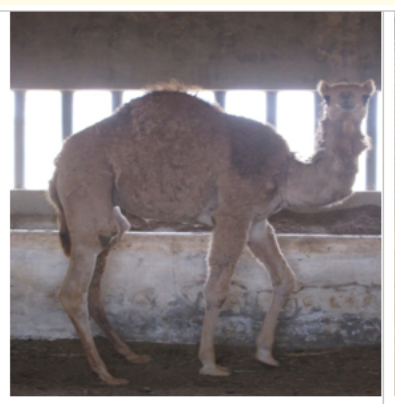

Housing of calves

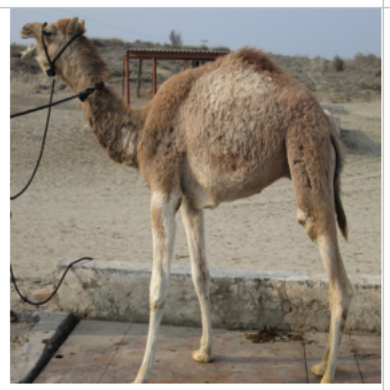

Weighing of calves

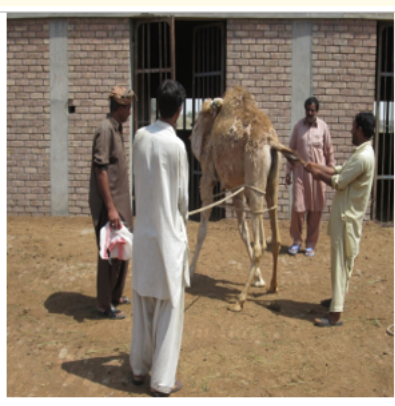

Handling of calves

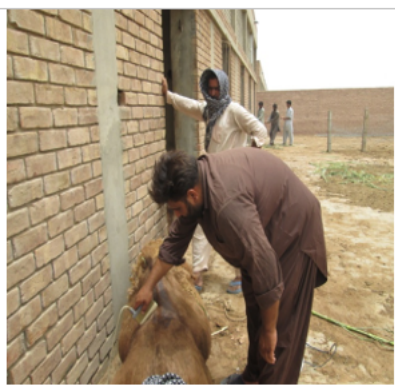

Back fat layer detection by ultrasonography
Figure 1: Housing, handling, weighing and back fat layer detection by ultrasonography in Marecha camel calves.

\section{Conclusion}

Ultrasonography has offered the potential to produce accurate and quick measurement at lower cost. In tracking the carcass 
merit, ultrasonography used to be a substitute for serial slaughtering. It is a very simple and reliable technique for subcutaneous fat measurement. Rump fat depths can be measured very accurately by ultrasonography. Sternal recumbency is the most suitable position to perform ultrasonographical examination; technique is noninvasive and could be applied on non-tranquilized camels.

\section{Acknowledgements}

The author gratefully acknowledges the kind support of management of Camel Breeding and Research Station (CBRS) RakhMahni for camel research.

\section{Data Availability Statement}

All relevant data are within the paper and supplementary materials.

\section{Funding}

The Higher Education Commission (HEC) Islamabad, Pakistan.

\section{Competing Interests}

There is no competing interest.

\section{Bibliography}

1. Faraz A., et al. "The camel-a short communication on classification and attributes". Journal of Fisheries and Livestock Production 7 (2019): 289.

2. Raziq A., et al. "Camel - A potential dairy animal in difficult environments". The Pakistan Journal of Agricultural Sciences 45.2 (2008): 263-267.

3. Faraz A., et al. "Socio-economic status and associated constraints of camel production in desert Thal Punjab, Pakistan". Journal of Fisheries and Livestock Production 7 (2019): 288.

4. Faraz A., et al. "Role of camel in food security: a perspective aspect". Journal of Fisheries and Livestock Production 7 (2019): 290.

5. Faraz A., et al. "Production potential of camel and its prospects in Pakistan". Punjab University Journal of Zoology 28 (2013): 89-95.

6. Faraz A and Waheed A. "The Camel, LAMBERT Academic Publishers (2019).

7. Faraz A. "Portrayal of camel production in the desert ecosystem of Pakistan". Journal of Zoological Research 2 (2020): 1520.
8. Suzuki R., et al. "Abdominal wall fat index, estimated by ultrasonography, for assessment of the ratio of visceral fat to subcutaneous fat in the abdomen". The American Journal of Medicine 95.3 (1993): 309-314.

9. Tornaghi G., et al. "Anthropometric or ultrasonic measurements in assessment of visceral fat? A comparative study". International Journal of Obesity and Related Metabolic Disorders 18.11 (1994): 771-775.

10. Armellini F., et al. "The contribution of sonography to the measurement of intra- abdominal fat". Journal of Clinical Ultrasound 18.7 (1997): 563-567.

11. McLaren DG., et al. "A study of operator effects on ultrasonic measures of fat depth and longissimus muscle area in cattle, sheep and pigs". Journal of Animal Science 69 (1991): 54-66.

12. Merino-Ibarra E., et al. "Ultrasonography for the evaluation of visceral fat and the metabolic syndrome". Metabolism 54 (2005): 1230-1250.

13. Brethour JR. "Modeling rate of increase in back fat thickness in feedlot steers". Journal of Animal Science 66 (1988): 453.

14. Brethour JR. "The repeatability and accuracy of ultrasound in measuring backfat of cattle". Journal of Animal Science 70 (1992): 1039-1044.

15. Robinson DL., et al. "Live animal measurement of carcass traits by ultrasound: assessment and accuracy of sonographers". Journal of Animal Science 70 (1992): 1667-1676.

16. Elnahas A. "Ultrasonographical examination of one humped camels (Camelus dromedarius) liver with some hematological and biochemical aspects". A thesis submitted to der Veterinarmedizinischen Fakultat, Leipzig, Germany (2008).

17. Fernandez C., et al. "Using ultrasound to determine fat thickness and longissimus dorsi area on Manchego lambs of different live weight". Small Ruminant Research 27 (1988): 159-165.

18. Silva SR., et al. "In vivo estimation of sheep carcass composition using real-time ultrasound with two probes of 5 and 7.5 $\mathrm{MHz}$ and image analysis". Journal of Animal Science 84 (2006): 3433-3439.

19. Wilson DE. "Application of ultrasound for genetic improvement". Journal of Animal Science 70 (1992): 973-983.

20. Hopkins DL. "Predicting the weight of lean meat in lamb carcasses and suitability of this characteristic as a basis for valuing carcasses". Meat Science 38.2 (1994): 235-241. 
21. Jones., et al. "The prediction of saleable meat yield in lamb carcasses". Canadian Journal of Animal Science Journal 76 (1996): 49-53.

22. Kirton $\mathrm{AH}$ and Johnson DL. "Interrelationships between GR and other lamb carcass fatness measurements". Proceedings of the New Zealand Society of Animal Production 39.5 (1979): 194-201.

23. Theriault M., et al. "Accuracy of real-time ultrasound measurements of total tissue, fat, and muscle depths at different measuring sites in lamb". Journal of Animal Science 87 (2009): 1801-1813.

24. Faraz A., et al. Growth performance, body condition scoring, back fat layer measurement and economics of weaned camel calves fed diets with two protein levels. Proceeding's 5th conference of the International Society of Camelid Research and Development (ISOCARD). "Recent advances in Camelid's biology, health and production Laayoune Morocco". (2018): 435437.

\section{Assets from publication with us}

- Prompt Acknowledgement after receiving the article

- Thorough Double blinded peer review

- Rapid Publication

- Issue of Publication Certificate

- High visibility of your Published work

Website: www.actascientific.com/

Submit Article: www.actascientific.com/submission.php

Email us: editor@actascientific.com

Contact us: +919182824667 